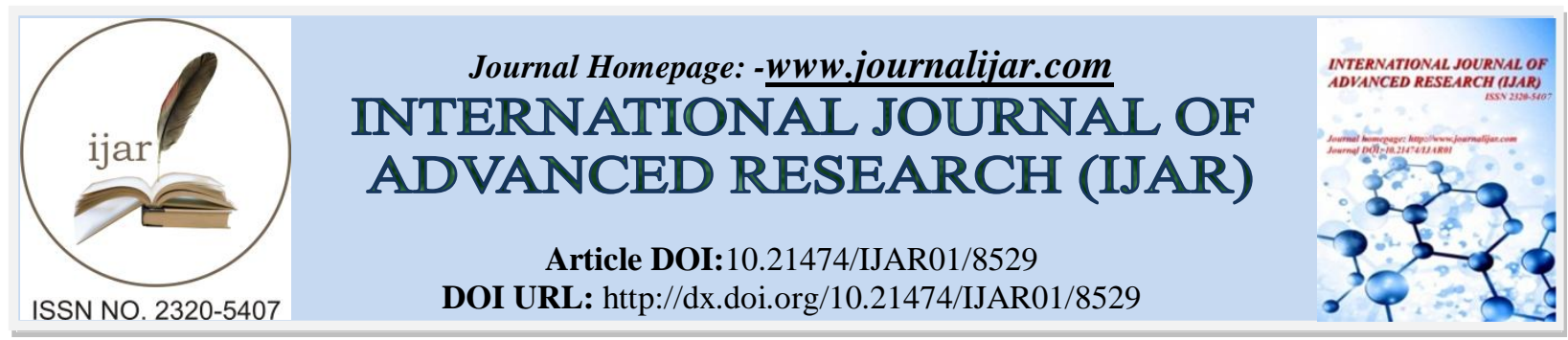

RESEARCH ARTICLE

\title{
"IMPACT OF FISCAL DEFICIT ON ECONOMIC GROWTH: AN EMPIRICAL STUDY OF INDIAN ECONOMY."
}

Khurshid Ali.
Assistant Professor, Higher Colleges of Technology, Abu Dhabi, United Arab Emirates.

\section{Manuscript Info}

Manuscript History

Received: 06 December 2018

Final Accepted: 08 January 2019

Published: February 2019

Key words:-

Gross Domestic Product, Fiscal Deficit, Macro-economic Imbalances, Linear Regression Model, Pearson's Correlation Model.

\begin{abstract}
This study has been undertaken so as to establish the impact of fiscal deficit on the growth of gross domestic product. In order to achieve the objective of the study, the researcher has taken a reference period of fifteen years from 1999-2000-20013-2014. The researcher has employed linear regression model and Pearson's correlation model. The findings of the study through linear regression model confirm that the independent variable (Fiscal Deficit)is significant in causing a change in the dependent variable (Gross Domestic Product).Besides, the results of Pearson's correlation model also affirm a negative relationship between the variables under study at 0.05 level of significance. The findings of the study corroborates with the findings of Mohammad et.al. (2010), Vincent et.al. (2012), Gemme (2001), Hernes and Censink (2001) and Candan (1983) as all these studies also established a negative relationship between fiscal deficit and gross domestic product.
\end{abstract}

Copy Right, IJAR, 2019,. All rights reserved.

\section{Introduction:-}

Although the introduction of paper standard facilitated the governments all over the world in the expansion of public expenditure so as to bring about social welfare yet it has brought about a major macroeconomic imbalance in the form of fiscal deficit. Now-a-days many a countries are battling the consequences of ballooning fiscal deficit. Therefore, fiscal policy has to be formulated with utmost care for a slight ignorance can get the whole fiscal affairs in a mess. A country has to balance its fiscal affairs in such a way as she can achieve sustainable growth and macroeconomic stability.

The fiscal deficit of India jumped to 6.5 per cent of the gross domestic product in the financial year 2009-10 but the right policy measures put it on the downward trajectory since then and is now expected to be contained at 4.8 per cent of the gross domestic product for the financial year 2013-14. Despite, all the drawbacks of deficit financing, it has now been recognised as a tool in the management of economic affairs of a country, particularly, in developing countries, like India where there is a tremendous need to develop infrastructure for social welfare as well as for corporate growth.

A country facing revenue and expenditure mismatches has to resort to deficit financing to not only overcome macroeconomic imbalances but also to finance investments. But, this fiscal deficit has to be contained under comfortable levels for higher fiscal deficit on the one hand adversely influences economic growth and on the other hand down grades the global ratings of the country. This situation discourages the foreign investor to invest in the country, besides, the borrowing from the international debt and capital markets become difficult and 
expensive.Thus, it can be said that deficit financing is a double edged sword that needs to be managed with great expertise, otherwise, it can do more of harm than service to the economy of a country.

\section{Review of Literature:-}

Now-a-days deficit financing is a burning question all over the globe, therefore, it has attracted the attention of academicians who have undertaken a lot of research on the spillover effects of fiscal deficit on the macroeconomic variables. The researchers in this regard have undertaken the review of some major studies which is given below.

Mohammad et.al. (2010) undertook a study and the results confirmed an inverse relationship between public debt and economic growth. Vincent et.al. (2012) analysed the impact of fiscal deficit on the economic growth and the findings of the study puts forth that there exists inverse relationship between fiscal deficit and economic growth. The study shows with empirical evidence a one per cent increase in fiscal deficit is capable of dampening economic growth by about 0.023 per cent. Gemme (2001) made a study on low income, medium and high income countries and the results established significant negative effect of fiscal deficit on economic growth.

Hernes and Censink (2001) analysed the impact of fiscal deficit financing on the economic growth in a detailed manner and concluded that deficit financing not only increase interest rates in the financial markets but it also brings about contraction in private investment, thereby, adversely influencing the economic growth. Candan (1983) used a sample of 96 developing countries to determine the relationship between fiscal deficit and economic growth. He concluded in his study that larger fiscal deficits reduce economic growth. The World Economic Outlook (IMF-1996) concluded in their report that during the mid-80s a group of countries with high fiscal imbalances had achieved significantly lower economic growth than the countries with low to medium budget deficits.

Baldacci et.al. (2003) concludes in their study that a reduction in the average deficit in low income countries from 4 per cent of Gross Domestic Product to 2 per cent of Gross Domestic Product could boast per capita growth by about half to one per centage point. Okelo et. al. (2012) undertook a study on Kenya and concluded that fiscal deficits can increase economic growth as it enhances productivity by providing better infrastructure. The study, therefore, affirmed a positive relationship between economic growth and fiscal deficit. Brauninger (2002) conducted a study on the interaction of budget deficit, public debt and endogenous growth. The findings puts forth that as long as fiscal deficit stays below a critical level, the economic growth moves in an upward trajectory. Adam and Bevan (2004) made an empirical study to examine the relationship between fiscal deficit and economic growth of fourty five developing countries. The study concluded that fiscal deficit around 1.5 per cent of Gross Domestic Product can be growth enhancing.

Objectives of the study:-

1. To determine the impact of fiscal deficit on the Gross Domestic Product.

2. To examine the relationship between fiscal deficit and Gross Domestic Product.

\section{Hypothesis:-}

Null Hypothesis:

Fiscal deficit does not influence Gross Domestic Product.

\section{Alternate Hypothesis:-}

Fiscal Deficit influences Gross Domestic Product.

\section{Null Hypothesis:}

There exists no relationship between fiscal deficit and Gross Domestic Product.

\section{Alternate Hypothesis:}

There exists a relationship between fiscal deficit and Gross Domestic Product.

\section{Methodology:- \\ Data Base:-}

In order to achieve the objectives of the study, the researcher has taken a reference period of fifteen years from 1999-2000 to 2013-2014. In the study only secondary data has been employed that has been collected from the 
official website of Planning Commission of India. The researcher has employed linear regression modeland Pearson's correlation model so as to arrive at dependable conclusion.

\section{Results and Discussion:-}

\section{(Model )I:-}

Linear regression model:-

The employment of linear regression model through SPSS has put forward the output in the form of the following three tables which are discussed below in detail.

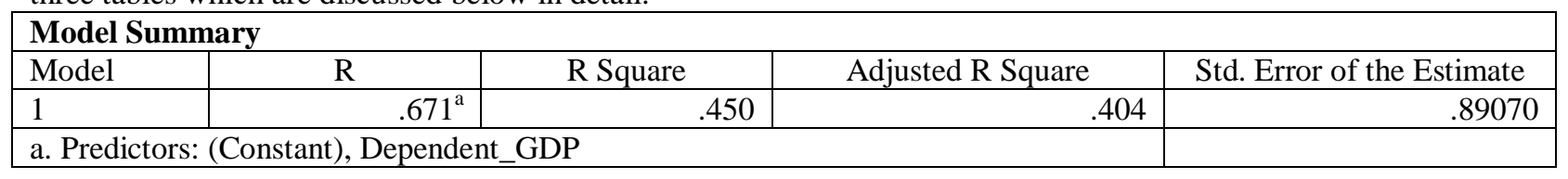

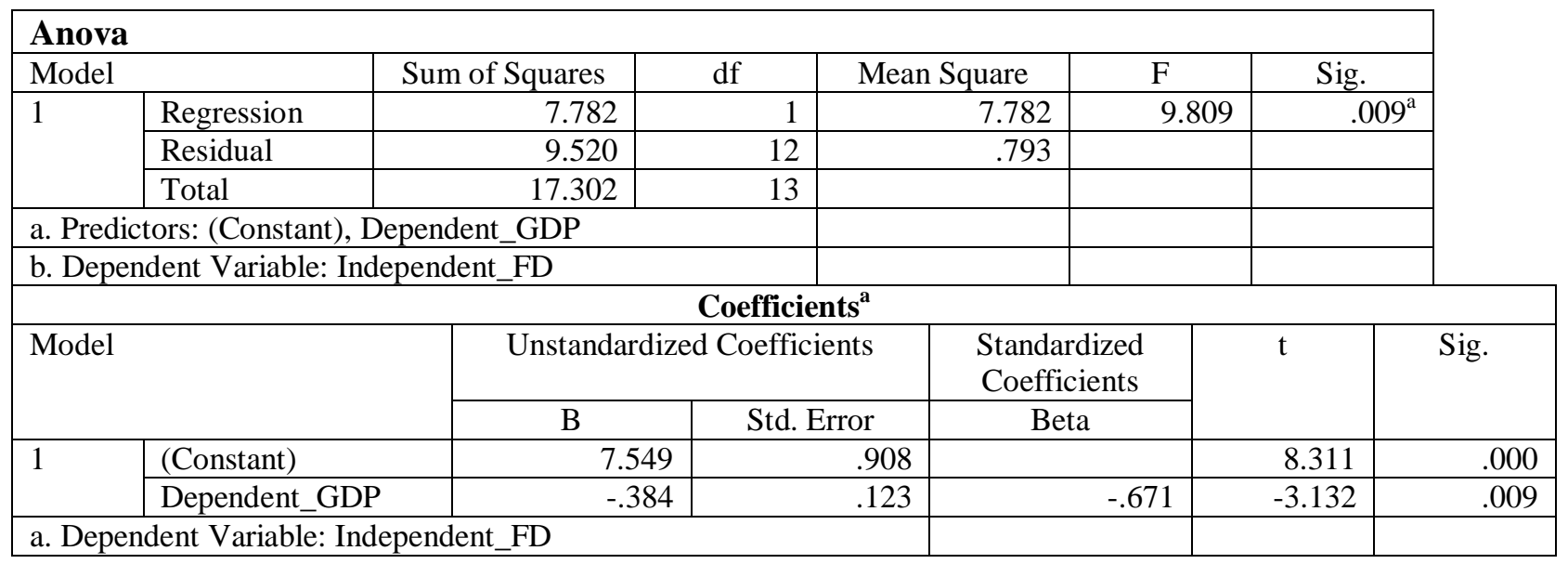

After employing the linear regression model, the findings put forth by the model affirm that the independent variable influences the dependent variable statistically in a significant manner, thereby, establishing the rejection of null hypothesis. The findings are confirmed by $\mathrm{R}$ squared which stands at 0.45 implying that the independent variable causes 45 per cent variation in the dependent variable. The results are further established by analysis of variation test in which the significance of variance stands at 0.009 which is less than 0.05 level of significance. In the table of coefficients the $B$ value is -0.384 that represents the extent to which the value of independent variable contributes to the value of dependent variable, thus, it is established statistically that if fiscal deficit changes by one unit, it will reflect a change of -0.38 per cent per unit in gross domestic product. The $\mathrm{T}$ value supports the same with a significance value of 0.009 .

\section{Model II:-}

Pearson's correlation model:-

The employment of Pearson's correlation model through SPSS has put forward the output in the form of the following two tables which are discussed below in detail.

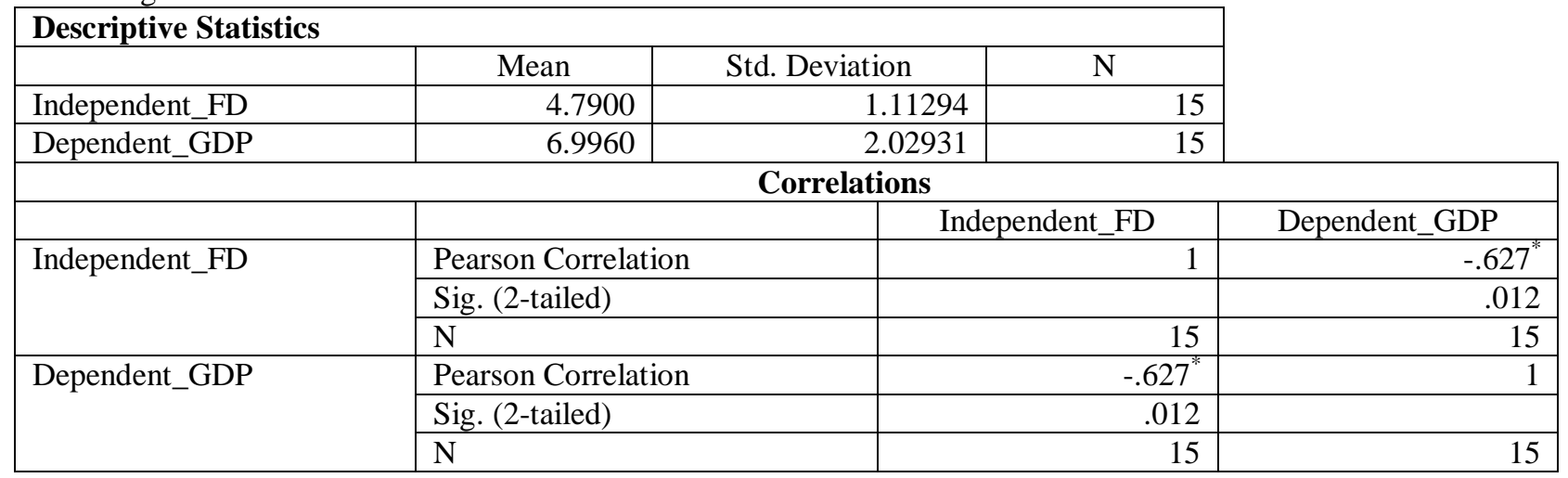


*. Correlation is significant at the 0.05 level (2-tailed).

The results of the correlation matrix confirm an inverse relationship between fiscal deficit and gross domestic product. From the table, it can be seen that the relationship coefficient stands at -0.627 and the significance of 2tailes test is 0.012 which is less than 0.05 level of significance, thereby, establishing statistically significant correlation between fiscal deficit and gross domestic product.

\section{Conclusion:-}

The growth of Gross Domestic Product is the most significant indicator of the health of an economy. Hence, in the study, the researcher has made an attempt to establish whether fiscal deficit influences gross domestic product or not. After employing the linear regression model and Pearson's correlation model, results establish that fiscal deficit significantly influence gross domestic product in a significant way. Besides, linear regression model, Pearson's correlation model is also employed which established negative relationship between the variables under study.Thus, it may be conclude on the basis of the findings of the study that fiscal deficit negatively influences gross domestic product. The findings of the study corroborate with the findings of Mohammad et.al. (2010), Vincent et.al. (2012), Gemme (2001), Hernes and Censink (2001) and Candan (1983) as all these studies also established a negative relationship between fiscal deficit and gross domestic product.

\section{Reference:-}

1. Adam, C. S. And Bevan D. L. (2004), "Fiscal Deficits and Growth in Developing Countries." Journal of Public Economics, Vol. 89, pp. 511-597.

2. Brauninger M. (2002), "The Budget Deficit, Public Debt and Endogenous Growth.” Journal of Economics, Vol. 63, No. 41, pp. 1-15.

3. Gemmel N. (2001). "Fiscal Policy in a Growth Framework." World Institute for Development Economic Research, Discussion Paper, No. 2001/84, pp. 1-23.

4. Vincent N. Ezeabasili and Ioraver N. Tsegba (2012), "Economic Growth and Fiscal Deficits" Economics and Finance Review Vol. 2(6) pp. 85-96.

5. Badacci E. Clement B. and Gupta S. (2003), "Using Fiscal Policy to Spur Growth." Finance and Development, pp. 28-31.

6. Okelo Simeo Odhiambo et.al. (2012), "The Relationship Between Fiscal Deficits and Economic Growth in Keniya: An Empirical Investigation."

7. Sheikh R. Mohammad et.al. (2010), "Domestic Debt and Economic Growth in Pakistan: An Empirical Analysis." Pakistan Journal of Social Sciences (PJSS), Vol.3o, No.2, pp. 373-387.

8. Hermes N. And Robert Lensink (2001), "Fiscal Policy and Private Investment in Less Developed Countries. Discussion Paper. No. 2001/32, United Nations University/ WIDER, July IMF.

9. Landau D. L. (1983), "Government Expenditure and Economic Growth: A Cross Country Analysis." Southern Economic Journal, Vol. 49, pp. 783-792.

10. Report of World Development Outlook (IMF-1996). 